\title{
Combining Usability Testing with In-Depth Interview for Online Credit Hour Website Evaluation
}

\author{
Pristi Sukmasetya*, Endah Ratna Arumi, Agus Setiawan \\ Department of Informatic Engineering \\ Universitas Muhammadiyah Magelang \\ Indonesia \\ Correspondence: pristi.sukmasetya@ummgl.ac.id
}

\begin{abstract}
The Online Credits Hour (KRS) application is one of the existing systems at the University of Muhammadiyah Magelang where the academic community, including lecturers, students, and education staff, produces a large amount of student academic data. Evaluation is necessary to find out whether the system runs well. This study is an effort to evaluate the system employing a usability test consisting of five indicators, namely learning ability, memory, efficiency, errors, and satisfaction. The five indicators materialized in the form of questionnaires to online KRS users. The survey involved 118 respondents. The method of study includes validity and reliability tests. The validity test employs a correlation test. The reliability test uses a simple linear regression analysis test and the comparison uses the significance value Alpha equals 0.05 . The validity test for all five indicators results in value above 0.05 . The reliability test of all the answers in the questionnaire has a Cronbach's Alpha value of 0.93 , which suggests that the whole has correspondence. The evaluation results show that the KRS Online application has the highest value in the memorability indicator at 3.97, indicating that the KRS Online application is easily accessible with easy procedures to obtain data. The lowest value is on the error indicator at a level of 3, which means that the KRS Online website shows many errors, such as a broken link or poor navigation.
\end{abstract}

Keywords: usability, usability testing, usability evaluation

Article info: submitted April 30, 2020, revised June 15, 2020, accepted July 24, 2020

\section{Introduction}

Nowadays, the development of the internet and information technology made many opportunities from various sectors and provided many benefits [1], [2]. Not only providing opportunities in the goods and services sector, but the internet and information technology provide many benefits to the education sector [3]. One of the uses of information and communication technology that is already widely used in the education sector is especially for universities and government [4], [5].

One of the uses of information and communication technology in tertiary institutions is the existence of an online credit hour form (KRS) website that makes it easy for students and lecturers to track academic activities that take place at tertiary institutions. Based on the benefits gained by the existence of this KRS Online Website, it is appropriate for universities to develop and maintain the existing KRS Online Website optimally. However, in reality, it is still rare for universities to spend more effort to evaluate information technology [6], applications, and websites owned [7], [8] as the KRS Online Website alone. It is essential to conduct this evaluation, considering the online KRS website as one of the sites that are often used by the academia (be it students, lecturers, education staff) to record the academic footprint of students with an insignificant amount of data [8].

This evaluation will be useful to find out how effective and efficient it is [5]-[9] from the KRS Online Website for users. This evaluation will also be beneficial, as one of the bases for developing a website, if you add a few features in the future. Evaluations that have been done separately to find out how far the utilization of a technology or application is one of them is using usability analysis [3]. Usability is part of the science of Human-Computer Interaction, which focuses on studying interface design and interactions between humans and computers [10], [11], [12]. This usability study will discuss user experience in learning and using certain technologies, applications, or websites [9]. Existing indicators on usability are also used to measure how satisfied the user is in using the technology, application, or product to achieve goals. In this case, the measure of success can be seen from how well an application or technology is in providing quality service 
to users [13], [14]. Not only can that, but also how far the application of technology reduces the possibility of errors that occur so that the learning process in using forms is easily obtained [16].

There are five indicators [14], [15] used in this research. Those indicators used to determine the quality of a website is interacting with its users. Learnability is one indicator of usability that is used to find out how easy it is for users to learn websites that are used in fulfilling existing tasks. The second indicator is memorability. Memorability is an indicator that is used to determine the extent of user convenience considering how to use a website if, after all this time, is not using it.

Furthermore, efficiency is an indicator that is used to find out how efficiently the users are doing some of the tasks available in the application. Errors are indicators that are used to find out how many mistakes are made by users when using a website and are related to the user's way of correcting errors. Satisfaction is an indicator that explains the level of user satisfaction in utilizing a site[16].

Some research that tries to evaluate websites using usability shows that usability can describe in more detail related to user experience in using specific applications or systems. Indeed, some things that benefit from knowing the conditions of experience and user satisfaction in using an app or system include able to increase the efficiency of the system itself [15]-[17]. Even from the appearance side, if the appearance design of the application is more user friendly and easy to use, the user does not need to spend much time just to understand and repeatedly ascertain the purpose of the appearance of the application or system.

When software does not meet usability criteria, users will spend too much time understanding the interface, thus making them less efficient at work and it can increase productivity. The excellent interface allows users to concentrate more on their work than on the device they are using less training. Therefore, time and costs can be reduced. A usable product will also reduce problems experienced by users, and because of that, support for the product can also be reduced. Increased acceptance, when users like the system because of its proper nature, they will be more comfortable in using it. Reducing development costs making changes from the start in the design life cycle is much cheaper than making it at the end of increased sales. The usefulness of a system can be superior competitiveness when compared to other products. For this reason, the focus of this research is to evaluate the existing KRS Online Website at universities with usability testing and in-depth interviews to find out the extent of the use of the system. The purpose of this study was to determine the level of usability on the KRS website.

\section{Method}

In this study, what will be the object is the online KRS site owned by the University of Muhammadiyah Magelang (krsol.ummgl.ac.id). The research to be carried out, in this case, is a combination of qualitative and quantitative analysis using five indicators that exist in usability testing. There are four stages carried out to implement this method, namely the exploration of concepts and identification of problems, data collection, data analysis, and finally, the results and discussion.

a. Exploration of Concepts and Identification of Problems In the initial stages of the study, the exploration begins of concepts and identification of problems. It was carried out with a literature study related to the ideas that will be used in this research. The literature studies sought as a reinforcement of the concept include usability, usability evaluation, usability testing, website user experience, and matters relating to human-computer interaction. The results of this literature study will be used to strengthen the basic concepts that will be used as a reference for the data analysis process and identify existing problems.

b. Data Collection

At the data collection stage, the first thing to do is to make a research instrument. In this study, the research instrument is made in the form of a questionnaire by lowering statement items from the five indicators that exist in usability testing. The five indicators used are learnability, memorability, efficiency, errors, and satisfaction. The five indicators will be derived into several statement items for each indicator that represents the user experience in using the KRS Online Website. This questionnaire will be distributed with a purposive sampling approach to the academic community of the University of Muhammadiyah Magelang using the KRS Online Website.

Table 1 explains the coding and statement items derived from the five usability testing indicators. In its assessment, this instrument uses a Likert Scale, with five response choices, namely strongly disagree (SD), disagree (D), neutral $(\mathrm{N})$, agree $(\mathrm{A})$, strongly agree $(\mathrm{SA})$, with the range of scores on positive items being 1-5. Apart from the questionnaire, additional data will also be collected through a series of interviews with several IT experts to strengthen the evaluation results from the KRS Online Website obtained through the questionnaire. For gaining more perspective about the experience of the user. We choose seven users to conduct an in-depth interview. This interview process aims to explore further the aspects of users regarding the use of the application. The ten people chosen to be interviewed the following qualifications, the first is that the user must be a student from the University of Muhammadiyah Magelang. The user must include inactive users of the application, which means they use the app for at least three years in a row. The questions raised in this depth-interview process is about the user's experience while using the application, what obstacles are often experienced, and the user's assessment of the application. The interview was carried out for approximately fifteen minutes per person. 
Table 1. Coding and Item Questionnaire Statement

\begin{tabular}{|c|c|c|}
\hline Indicator & Code & Statement of the Questionnaire \\
\hline \multirow{5}{*}{$\begin{array}{l}\text { Learnability } \\
\text { (A) }\end{array}$} & (A1) & The KRS Online website can be learned easily \\
\hline & (A2) & I easily and quickly receive detailed and specific information on KRS online \\
\hline & (A3) & I can quickly understand the contents and information content presented on the KRS Website online \\
\hline & (A4) & $\begin{array}{l}\text { I was able to quickly understand and understand the flow of navigation available on the online KRS } \\
\text { Website }\end{array}$ \\
\hline & (A5) & Without written instructions or a manual book, I was able to study the use of the KRS Website online \\
\hline \multirow{3}{*}{$\begin{array}{l}\text { Memorability } \\
\text { (B) }\end{array}$} & (B1) & I can easily remember the use of the KRS Online Website \\
\hline & (B2) & I can easily find out and remember navigation directions and features on the online KRS Website \\
\hline & (B3) & I find it easy whenever using the KRS website online \\
\hline \multirow[t]{3}{*}{ Efficiency (C) } & $(\mathrm{C} 1)$ & I was able to access the menu on the KRS Website online quickly \\
\hline & $(\mathrm{C} 2)$ & I easily obtained information about the KRS Online Website \\
\hline & (C3) & $\begin{array}{l}\text { I was able to immediately find the information I wanted to find from the start opening on the KRS } \\
\text { Online Website Errors }\end{array}$ \\
\hline \multirow[t]{3}{*}{ Errors (D) } & (D1) & I found no errors when using the KRS Online Website \\
\hline & (D2) & I did not find an error menu or not following its function \\
\hline & (D3) & I can find the features and menus that I am looking for on the KRS Online Website \\
\hline \multirow{4}{*}{$\begin{array}{l}\text { Satisfaction } \\
\text { (E) }\end{array}$} & $(\mathrm{E} 1)$ & I am happy with the interface design that exists on the KRS Website online as a whole \\
\hline & (E2) & I feel comfortable using the KRS Website online \\
\hline & (E3) & The combination of colors and content layout is pleasant to look at \\
\hline & $(\mathrm{E} 4)$ & The KRS Online website is in line with my expectations when I see the title on the system page \\
\hline
\end{tabular}

c. Data Analysis

Analysis of the data to be used in this study uses a mixed-method approach or a combination of quantitative and qualitative data analysis. For quantitative analysis, it was using descriptive statistical analysis, which aims to find out the average evaluation results of the five indicators that exist in usability testing on the KRS Online Website. For qualitative analysis, it is carried out by transcribing the results of in-depth interviews with several KRS Online Website users and processing them with NVIVO Tools.

\section{Result and discussion}

a. Search Related Studies and Identification of Problems The first step we do is selecting some studies related to the concepts that will be used in this research. We try to search and retrieve from several journal articles and conference papers from the database, i.e., IEEE Xplorer, ACM Digital Library, AIS Electronic Library, Emerald Insight, ProQuest, and ScienceDirect/Scopus. It aims to gain more understanding about usability testing and in-depth interview concept. From the searching result, we found almost eleven papers that show the idea of usability testing and thorough interview and how we must do to solve the problems.

b. Analysis, Reliability and Validation Test

In distributing questionnaires, this research uses a purposive sampling method [18] to get respondents.
Which means, researchers first determine the conditions related to the intended respondent. The requirements applied in this study are, users of KRS Online, in this case, University of Muhammadiyah Magelang students. Before the questionnaire was distributed, two tests were first carried out. Reliability testing was conducted by selecting ten prospective respondents randomly to see to what extent potential respondents can understand the statements contained in the questionnaire. Furthermore, the Reliability Test is carried out whether or not the draft questionnaire will be distributed reliably. In conducting Reliability Tests, use SPSS tools.

Table 2. Questionnaire Instrument Reliability Test Results

\begin{tabular}{ccc} 
Cronbach's Alpha & $\begin{array}{c}\text { Cronbach's } \\
\text { Alpha Based on } \\
\text { Standardized Items }\end{array}$ & N of Items \\
\hline 0.934 & 0.936 & 18 \\
\hline
\end{tabular}

Table 2 shows the results of the reliability test conducted. The analysis found that Cronbach's alpha was 0.934, which means that the statement was received. After the questionnaire is confirmed valid and reliable, then the survey is distributed using the Google form electronic page within three weeks to get responses from respondents who have been determined. The period used to get respondents is for two weeks, from the results of the distribution of questionnaires obtained 118 respondents who have filled 
and assessed the University of Muhammadiyah Magelang KRS Online Website. Table 3 shows the delivery of the sample of respondents who entered and assessed the KRS Online Website.

Table 3. Number of Respondent Samples

\begin{tabular}{ccc}
\hline & Gender & Distribution \\
\hline Valid & Male & 84 \\
& Female & 34 \\
& Total & 118 \\
\hline
\end{tabular}

A validity test is done again after all the data from the respondents are collected. Those action becomes necessary to know and test the strength of conclusions and inferences from the test results to approach the truth [23]. This test is done by identifying the $r$ count of the value of existing items. If the value of $r$ count $>$ value of $r$ table, then the group question can be considered "Valid" [24]. The amount of $\mathrm{r}$ Table in this study is 0.325 obtained from the table $\mathrm{r}$ significance for two way testing with a value of 0.05 , and with degrees of freedom $\mathrm{n}-2$, it can be said to be valid. After the validity test is done, then the detailed statistical calculations are performed to see the results of the usability testing conducted.

c. Conducting Usability Testing and In-depth Interview The first process carried out in usability testing is to calculate the data that entered from the questionnaire using descriptive statistics. In this descriptive statistical calculation, the average results of usability testing conducted on the KRS Online Website are then divided into five categories and assessment ranges. If the average value of usability testing is in the field of $0<1$ then it can be stated that the Website belongs to a very bad category. The range of values of $1<2$ website is said to have a pretty lousy rating, for a variety of benefits of 2 $<3$, the Website is considered quite good, range 3 $<4$ websites are said to be good enough, and the Website is declared very good if the rating is in the range $4=<5$.

Table 4. Website Rating Categories and Range

\begin{tabular}{cc}
\hline Interval & Categories \\
\hline $0<1$ & Very Bad \\
$1<2$ & Bad Enough \\
$2<3$ & Good \\
$3<4$ & Pretty Good \\
$4=<5$ & Very Good \\
\hline
\end{tabular}

We can see from the result of grouping usability testing result that has been carried out, supported by qualitative data processing from the effects of in-depth interviews to several users of the KRS Online Website. It is found that the indicator of memorability is the aspect that has the highest rating, with a value of 3.97 , which means it is quite good. This can be said that users can easily remember and know the usage of the KRS Online Website. Followed on the second rank is the learnability indicator of 3.86, which means good enough, and it can be interpreted that KRS Online Website users find the Website easy to learn, both in terms of the flow and navigation provided by the Website. Not only that, without manual books or instructions for use, but users can also still run the KRS Online website as it functions. Efficiency becomes the third indicator with an assessment of 3.51, which means that it even exists in a reasonably good range. Users find that they can quickly get the information they want to see just by looking at the start page on the Website. Not only that, but users also feel able to do many activities (access) with a fast time. Next is the satisfaction indicator of 3.46 which is also included in the quite good category. Table 5 displays the average total results of each indicator from the usability assessment conducted.

Overall the use of the KRS Online Website, users feel that in terms of the design and interface provided by the Website makes users feel comfortable. Besides, user expectations are met when using the KRS Online Website. The latter is an error indicator with a value of 3.30, still in the good enough category. In dealing with existing errors, the KRS Online Website is rated by the user to be able to provide certain notifications in the event of an error. However, in some cases, users often encounter errors without notification. This causes the user experience in terms of dealing with existing errors.

After doing the calculation process using descriptive statistical analysis, the next thing to do is to make additional confirmation using the in-depth interview approach to find out more about the experience of KRS Online Website users. Seven students were confirmed with an in-depth interview approach to telling their experiences using the application. Of the seven students, was agreed that if the existing KRS Online Website felt it was easy enough to remember and know the usage of the application without the manual. From the interviews process, almost seven users agreed that the KRS Online Website was easy to learn, including the content and information provided was also easy to understand. The barriers that often occur in the user in using the application is, there is no notification when an error occurs in the use of the application. this makes some users confused about operating it. From two approaches that have been done, usability testing and interview can be drawn to a common thread, that overall this application is good enough to meet user needs. 
Table 5. Average of each Usability Indicators

\begin{tabular}{|c|c|c|c|}
\hline Code & Statement & Average & $\begin{array}{l}\text { Average/ } \\
\text { Indicator }\end{array}$ \\
\hline \multicolumn{4}{|c|}{ Learnability (A) } \\
\hline (A1) & The KRS Online website can be learned easily & 4.02 & 3.86 \\
\hline (A2) & $\begin{array}{l}\text { I easily and quickly receive detailed and specific } \\
\text { information on KRS online }\end{array}$ & 3.71 & \\
\hline (A3) & $\begin{array}{l}\text { I can quickly understand the contents and } \\
\text { information content presented on the KRS Website } \\
\text { online }\end{array}$ & 3.91 & \\
\hline (A4) & $\begin{array}{l}\text { I was able to quickly understand and understand } \\
\text { the flow of navigation available on the online KRS } \\
\text { Website }\end{array}$ & 3.84 & \\
\hline (A5) & $\begin{array}{l}\text { Without written instructions or a manual book, I was } \\
\text { able to study the use of the KRS Website online }\end{array}$ & 3.85 & \\
\hline \multicolumn{4}{|c|}{ Memorability (B) } \\
\hline (B1) & $\begin{array}{l}\text { I can easily remember the use of the KRS Online } \\
\text { Website }\end{array}$ & 4.19 & 3.97 \\
\hline (B2) & $\begin{array}{l}\text { I can easily find out and remember navigation } \\
\text { directions and features on the online KRS Website }\end{array}$ & 3.89 & \\
\hline (B3) & $\begin{array}{l}\text { I find it easy whenever using the KRS website } \\
\text { online }\end{array}$ & 3.82 & \\
\hline \multicolumn{4}{|c|}{ Efficiency (C) } \\
\hline (C1) & $\begin{array}{l}\text { I was able to access the menu on the KRS Website } \\
\text { online quickly }\end{array}$ & 3.47 & 3.51 \\
\hline$(\mathrm{C} 2)$ & $\begin{array}{l}\text { I easily obtained information about the KRS Online } \\
\text { Website }\end{array}$ & 3.56 & \\
\hline (C3) & $\begin{array}{l}\text { I was able to immediately find the information I } \\
\text { wanted to find from the start opening on the KRS } \\
\text { Online Website Errors }\end{array}$ & 3.50 & \\
\hline \multicolumn{4}{|c|}{ Errors (D) } \\
\hline (D1) & $\begin{array}{l}\text { I found no errors when using the KRS Online } \\
\text { Website }\end{array}$ & 2.90 & 3.30 \\
\hline (D2) & $\begin{array}{l}\text { I did not find an error menu or not following its } \\
\text { function }\end{array}$ & 3.42 & \\
\hline (D3) & $\begin{array}{l}\text { I can find the features and menus that I am looking } \\
\text { for on the KRS Online Website }\end{array}$ & 3.59 & \\
\hline \multicolumn{4}{|c|}{ Satisfaction (E) } \\
\hline (E1) & $\begin{array}{l}\text { I am happy with the interface design that exists on } \\
\text { the KRS Website online as a whole }\end{array}$ & 3.27 & 3.46 \\
\hline (E2) & I feel comfortable using the KRS Website online & 3.61 & \\
\hline (E3) & $\begin{array}{l}\text { The combination of colors and content layout is } \\
\text { pleasant to look at }\end{array}$ & 3.47 & \\
\hline (E4) & $\begin{array}{l}\text { The KRS Online website is in line with my } \\
\text { expectations when I see the title on the system page }\end{array}$ & 3.50 & \\
\hline
\end{tabular}

\section{Conclusion}

The aims and focus of this research are to evaluate the existing KRS Online Websites at universities with usability testing and in-depth interviews to find out the extent of the usefulness of the system. There are five indicators used to evaluate or evaluate the Website. Namely learnability, memorability, efficiency, errors, and satisfaction. The total sample of respondents in this study was 118 people. The test method used in this study includes a validity test consisting of a reliability test and a correlation test. While the significance of the Alpha value used in this study was 0.05. From the results of the data validity test conducted, all indicators have values above 0.05 .
From the reliability test results, all statements contained in the questionnaire also have a Cronbach's Alpha value of 0.93 , which means that all comments are in accordance. The evaluation results show that of the five existing indicators, the KRS Online Website has the highest value on the memorability indicator of 3.97. This means that the KRS Online Website is easy to remember navigation and its layout to get information. For the lowest value of the five indicators is the error indicator with a value of 3 , this means that the KRS Online Website is still found many errors or errors either on the broken link or on the existing navigation. For further research so that it can be combined again with various kinds of indicators, then the correlation between current indicators can be known so that they can see the important indicators. 


\section{Reference}

[1] N. Binti and N. Rozali, "Usability Testing on Government Agencies Web Portal : A Study on Ministry of Education Malaysia ( MOE ) Web Portal," 2015 9th Malaysian Softw. Eng. Conf., pp. 37-42, 2015.

[2] A. Setiawan, R. A. Widyanto, P. Studi, T. Informatika, F. Teknik, U. M. Magelang, and P. H. Bersama, "Evaluasi Website Perguruan Tinggi Menggunakan Metode Usability Testing," vol. 3, no. 3, pp. 295-299, 2018.

[3] Y. F. Qiu, Y. P. Chui, and M. G. Helander, "Usability Analysis of Mobile Phone Camera Software Systems," pp. 1-6, 2006.

[4] P. Sukmasetya, H. B. Santoso, and D. I. Sensuse, "Current E-Government Public Service on User Experience Perspective in Indonesia," 2018 Int. Conf. Inf. Technol. Syst. Innov., pp. 159-164, 2018.

[5] J. Wang, "Usability testing on a government training platform: A case study," 2010 2nd Int. Conf. Educ. Technol. Comput., vol. 2, pp. V2211-V2-214.

[6] D. I. Sensuse, P. Pudy, and P. Sukmasetya, "Improving e-Leaming through Knowledge Management," 2017.

[7] Z. Luo, Y. Wang, P. Wang, and A. Participants, "Usability Study on Railway Self-service Terminal Interface for the Elderly," 2018 11th Int. Symp. Comput. Intell. Des., vol. 1, pp. 157-160, 2018.

[8] A. Lodhi, "Usability Heuristics as an Assessment Parameter : for performing Usability Testing," 2010 2nd Int. Conf. Softw. Technol. Eng., vol. 2, pp. V2-256-V2-259, 2010.

[9] W. K. H. Zhevlwh, K. D. V Ehhq, G. Dqg, G. Ghshqgv, R. Q. Lwv, L. Dwwulexwhv, Z. Fryhuv, W. K. H. Ghwdlov, R. I. Kwpo, V. D. Q. G. Dovr, W. Duh, and F. Dqg, "Analysis of Website Usability Evaluation Methods," pp. 1043-1046, 2016.

[10] M. K. Othman, M. N. S. Sulaiman, and S. Aman, "Heuristic evaluation: comparing generic and specific usability heuristics for identification of usability problems in a living museum mobile guide app," Adv. Human-Computer Interact., vol. 2018, 2018.

[11] H. M. Az-zahra, "Usability Evaluation of User Interface in Badan Narkotika Nasional East Java Province Website," 2018 Int. Conf. Sustain. Inf. Eng. Technol., pp. 262-265, 2018.

[12] D. Quiñones and C. Rusu, "Applying a methodology to develop user experience heuristics," Comput. Stand. Interfaces, vol. 66, p. 103345, 2019.

[13] R. Kaur, "Comparative Study for Evaluating the Usability of Web Based Applications," 4th Int. Conf. Comput. Sci., 2018.
[14] E. Palagi, F. Gandon, A. Giboin, and R. Troncy, "A model-based heuristic evaluation method of exploratory search," 2018.

[15] Z. Ebnehoseini, M. Tara, M. Meraji, K. Deldar, F. Khoshronezhad, and S. Khoshronezhad, "Usability evaluation of an admission, discharge, and transfer information system: a heuristic evaluation," Open access Maced. J. Med. Sci., vol. 6, no. 11, p. 1941, 2018.

[16] Y. Forster, S. Hergeth, F. Naujoks, J. F. Krems, and A. Keinath, "Empirical validation of a checklist for heuristic evaluation of automated vehicle HMIs," in International Conference on Applied Human Factors and Ergonomics, 2019, pp. 3-14.

[17] R. Khajouei, M. Zahiri Esfahani, and Y. Jahani, "Comparison of heuristic and cognitive walkthrough usability evaluation methods for evaluating health information systems," J. Am. Med. Informatics Assoc., vol. 24, no. e1, pp. e55e60, 2017.

[18] M. D. C. Tongco, "Purposive sampling as a tool for informant selection.," Ethnobot. Res. Appl., vol. 5, pp. 147-158, 2007. 